This is an electronic reprint of the original article. This reprint may differ from the original in pagination and typographic detail.

Author(s): Vuorisalo, Mari; Rutanen, Niina; Raittila, Raija

Title: Constructing relational space in early childhood education

Year: $\quad 2015$

Version:

Please cite the original version:

Vuorisalo, M., Rutanen, N., \& Raittila, R. (2015). Constructing relational space in early childhood education. Early years: an international journal of research and development, 35(1), 67-79. https://doi.org/10.1080/09575146.2014.985289

All material supplied via JYX is protected by copyright and other intellectual property rights, and duplication or sale of all or part of any of the repository collections is not permitted, except that material may be duplicated by you for your research use or educational purposes in electronic or print form. You must obtain permission for any other use. Electronic or print copies may not be offered, whether for sale or otherwise to anyone who is not an authorised user. 


\title{
Constructing relational space in early childhood education
}

\section{Mari Vuorisalo, Niina Rutanen and Raija Raittila}

Mari Vuorisalo, $\mathrm{PhD}$, the corresponding author

Department of Education

University of Jyväskylä, Finland

Email: mari.vuorisalo@jyu.fi

Niina Rutanen, PhD

School of Education

University of Tampere, Finland

Raija Raittila, $\mathrm{PhD}$

Department of Education

University of Jyväskylä, Finland

\begin{abstract}
This paper examines early childhood education (ECE) by applying and developing relational-spatial perspectives on everyday life in educational institutions for young children. The aim is to investigate the dynamic process of construction of space and to illustrate with selected empirical episodes how this process occurs in ECE. Drawing on authors such as Soja and Bourdieu, the starting point for the analysis is that space is socially produced in everyday interactions in a process that intertwines the physical environment and concrete objects, personal interpretations of physical and cultural space, and cultural and collective views about space in ECE (Soja 1996). We illustrate this process with ethnographic data from two day care centres. The analysis shows how children and educators engage in the process of constructing space from diverse positions and how the institutional context is embedded within this process.
\end{abstract}

Keywords: relational space; early childhood education; relational production of space; children's agency; doxa; ethnography 


\section{Constructing relational space in early childhood education}

\section{Introduction}

This paper discusses early childhood education (ECE) by applying and developing relational-spatial perspectives on daily life in educational institutions (Bourdieu 2000; Soja 1996). Various theoretical developments that could be regarded as 'relational perspectives' have been discussed recently in studies addressing childhood geographies and childhood sociology and in multidisciplinary childhood studies (e.g. Alderson and Jones 2009; Nordtømme 2012; Ryan 2012; Kjørholt and Seland 2012; Kallio and Häkli 2013; Skelton 2013; Harrison and Sumsion 2014). While the concept of space is widely discussed in childhood geography in the context of older children and youth participation, in ECE research the concept of space has remained in the margins until recently. Previous studies on ECE addressing space have focused on children's perception and use of physical space (Einarsdottir 2005), the assessment and evaluation of pedagogical and physical space in terms of the quality of care (Sylva 2010; Pessanha, Aguiar and Bairrão 2007), and children's participation and agency in certain spaces or learning environments (Emilson and Folkesson 2004). Instead of examining physical space, our aim was to focus specifically on the process of construction of space and to discuss it theoretically. By applying selected theoretical developments from geography and sociology, we provide critically reflected alternative means of interlinking the theoretical understanding and empirical analysis of individual action with the structural contexts for the construction of space in the institutional context of ECE (see also Mannion 2007).

The day care context is not, however, fixed, but continuously negotiated, re-constructed and reorganized. It includes both nonverbal and verbal negotiations among the participants about 'what is going on here', about the rules and limits that maintain the pedagogical space and institution (e.g. Markström 2010). These structural constraints are present in the background, setting the limits for the functioning of the group and shaping the possibilities for individual children's and educators' actions (Olwig and Gulløv 2003; Gallacher 2005; Löfdahl and Hägglund 2007).

The aim of this paper is to examine the process of construction of space in early childhood education and care by applying previous relational approaches in close dialogue with our empirical material.

\section{Relational approach to examining institutional ECE spaces}

Drawing on authors such as Edward Soja (1996), and Pierre Bourdieu (2000), our starting point is that space is relationally produced in everyday actions. This refers to the process that intertwines the physical environment and concrete objects, personal interpretations of physical and cultural space, and cultural and collective views about the space of ECE.

Edward Soja's (1996) concepts of 'Firstspace', 'Secondspace' and 'Thirdspace' expand the multidimensional and relational character of the concept of space. This relational approach includes the notion of human and environment as being integrally related. They coexist in a dynamic process in which one cannot be determined without the other. The basis of the human-environment relationship is the intertwining of the physical, observable environment (Firstspace) and a personal interpretation of the physical environment (Secondspace) (Soja 1996; see also Lefebvre 1991). Each individual sees and experiences the elements of the environment according to how they interpret them. These interpretations are individual and unique, and are associated with particular physical environment. Thus, individual interpretation is not independent of the previously planned and 
organized environment, but rather the environment directs or creates the potential for interpretation (Raittila 2008 and 2012). For example, the educators' and children's experiences and descriptions of the entrance hall of a kindergarten can be quite different, even though they concern the same physical environment. While the educators might describe this space as being too small and noisy, the children might find it highly attractive because it offers possibilities for free interaction while dressing to go outside.

However, the theories of space emphasize that there is also a third element of space. Soja's Thirdspace (1996, p. 9) is not possible to determine accurately, but offers a means of viewing and exploring the endless, renewable spatial themes. The Thirdspace includes the Firstspace and the Secondspace and brings the symbolism, politics and ideology of the culture, and collective meanings, rules and values to the entirety of the environment (Soja 1996, pp. 67-68, 81-82). Space is never a neutral context or background for action, but always involves collective definitions and ideas. These cultural and social aspects of the society shape individual interpretations of different spaces and provide a cultural lens. The organization and construction of the physical environment and the social meanings and rules attached to a space reflect certain expectations regarding how the space is used and who is using it. Because of the relational nature of the space, it is visible only by observing actions within its context. Through their actions, educators and children indicate (and tell) how they interpret the ECE space from their perspective. Space is formed continuously within the tangible and intangible institutional framework in which activities are addressed (Raittila 2012; Rutanen 2014 and 2014).

In this article, we explore the previously mentioned relational theoretical assumptions about space in light of the theoretical views developed by Pierre Bourdieu (2000). In our interpretation, Bourdieu's work (2000) resonates with the spatial approaches and the concept of 'Thirdspace', particularly in his discussion of 'doxa' (see also Deer, 2008). For Bourdieu, the social space is a 'field' that follows its 'natural' practice, called doxa. Bourdieu (2000, p. 16) defined doxa as 'a set of fundamental beliefs which does not even need to be asserted in the form of an explicit, selfconscious dogma'. Doxa refers to a sense of limits, in particular social space, in embodied form. Instead of explicit orders, doxa describes how participants in the social space follow its rules as an implicit and shared social habit. Thus, doxa gives structural balance to social space, but at the same time its essence as taken-for-granted rules means that it embraces power; some ways of acting are more expected than others. Following Bourdieu (2000), this is why it is important to examine social spaces and clarify what kinds of rules are followed in them. A precondition for participation in the social space is to recognize these rules, i.e. share the doxa of that particular space.

Shared cultural knowledge (Thirdspace, doxa) about ECE spaces constitutes the cultural lens with which the children and educators make decisions regarding their actions in the day care context (Raittila 2012, Rutanen 2014, Vuorisalo 2011). With their actions, children and educators (re)interpret and (re)construct the day care space from their individual positions and make it visible from their perspective. These two relational, mutually supportive, approaches by Soja (1996) and Bourdieu (2000) provide us the theoretical-methodological tools for studying institutional space. By applying this relational approach, the focus moves away from individuals, children and adults, to what is being produced relationally in action and interaction. The institutional setting offers a context, but it, too, is a product in the process of construction. This paper focuses on this process of continuous construction by applying the theoretical tools discussed above to illustrate the process.

\section{Ethnography in two different contexts}


The paper is based on two different data sets collected in ethnographic studies in two different day care groups in Finland. Data collection was also conducted in two separate projects, although these applied a similar relational approach in studying action and interaction within the institutional context of early childhood education in Finland (Rutanen 2012; Vuorisalo 2013).

The first day care group consists of one- to three-year-olds, and the second of six-year-olds (i.e. 'preschool' in the Finnish ECE system). The younger group comprised twelve children and three practitioners, including one preschool teacher and two nursery nurses. The preschool group included 21 children and three practitioners, two of them preschool teachers and one a nursery nurse. In Finnish day care centres, preschool teachers have the main pedagogical responsibility for the child group. However, the roles among nursery nurses and preschool teachers can vary considerably depending on the particular team or day care centre. Both groups were in day care centres run by Finnish municipalities. The data from the youngest group is in the form of video recordings, and the data from the group of six-year-olds is in the form of ethnographic field notes. Both sets of material were transcribed and transformed into electronic form.

Two episodes were selected for detailed analysis and illustration of the process of construction of space. There were three criteria for the selection: 1) The episodes are similar in that they both occur during the daily 'free play' time, which is the point in the daily routine when the children have most opportunities to negotiate the form and topic of their activity (e.g. puzzles, other games, play, looking at books) with each other and also with the practitioners. 2) The activity unfolds around the physical object: one has a low bench and the other a high jump stand. 3) The teachers observe the activity, but do not play as central a role in directing the children's actions. Some children actively participate, while others remain distanced from the activity. Both episodes represent how negotiations of space usually occur in these groups. However, the analysis is more like a theoretical experiment than a thorough analysis of the whole data set from both research projects. Harker (2005, p. 59) states that although play has the potential to be(come) spatially and temporally creative, playing can act to normalize spaces and bodies. We use these twofold ideas of play as being creative and normalizing as a starting point for examining how play sessions and relational space are simultaneously constructed in action.

The analysis is based on observation of the children's and educators' actions. The analysis proceeded from general characterization of the episodes to identifying children's and adult's strategies for constructing space. Initially, the content of actions and communication were described (what is happening and where, what are the children and educators doing) followed by reflection on 1) physical elements of the space used in the action and 2) personal interpretations of the use of the physical space. These personal interpretations were analysed in terms of speech and action. According to the relational view of the concept of space, the shared cultural space (Thirdspace) emerges only in processes in which people use the affordances of the space (Altman \& Rogoff 1987; Heft 2003). Affordances refer to what an environment offers or provides its users. However, these remain merely potential affordances if nobody uses them (Gibson 1977). Both halves of this relationship (environment and children/adults) are essential to the analysis of the cultural space (Thirdspace) of a day care centre. For example, if a bench is placed in the space for children to climb on, the space could be described as a "climbing space". Focusing on more specific sequences of events, we then examined the relationality of the observed actions by means of the analytical questions: What is being constructed and how? and How is the situation unfolding? Based on these questions, we interpret the space that the children and educators produce through the structures and positions that open up to the children; in other words, what is possible to be done, what is recognized as a possibility, and what is re-defined in action. 


\section{EPISODE 1: Children walking on a bench}

Before the episode described here, Kaarina (nursery nurse) has allowed some of the children to walk on the small benches, holding their hands for support.

Kaarina (nursery nurse) sits on a small bench and Venla (2 years 2 months) sits on her lap. Kaarina reads a book to Venla. Other children gather around them.

Meanwhile, Onni (1 year 7 months) starts to walk on a bench that is in front of them. Lauri (1 year 5 months) imitates Onni. Ritva (preschool teacher) enters the room, and the boys look towards her.

Ritva: 'Oh my, what're our little boys up to now!'

Kaarina: 'We were just learning how to walk on the bench.'

Ritva: 'I'll move that chair.' (moves a chair away from the bench.

Onni and Lauri look around. Other children observe them.)

Kaarina: 'Little boys, that Lauri is a bit small' (Lauri wobbles a little.)

Ritva: 'Oops!' (sits closer to the boys, moves the chair further away. Kaarina laughs.)

Ritva: 'It takes a bit of practice, but then..that's it..and sit'

(Kaarina and other children observe Lauri's actions. Lauri waves his body and sits down)

Ritva, watching Lauri, laughs and says: 'Oh dear'!

Kaarina and Ritva: 'Well done! Good!'

Kaarina: 'It's a lot safer with Onni...[Lauri's] still so small'

Rasmus (2 years 2 months) tries to climb onto the chair next to the bench.

Ritva: (in a discouraging tone) 'Rasmus!' (Rasmus withdraws; then Onni tries to climb onto the chair.)

Ritva: 'No, not on the edge, not allowed.' (Other children then distract the educators' attention. Onni climbs onto the chair and looks at Ritva, who doesn't notice him.)

In this episode, the physical environment of the day care centre and, particularly, the bench available in front of the two boys (Onni and Lauri), is a potential (physical) affordance that the boys interpreted as being suitable for climbing on and so they attempt to do so. The bench and the 'interpretative' action of the boys make the ECE space relationally visible. The boys experiment with their environment and the physical space around them nonverbally, with their bodies, climbing and stepping onto the bench. Onni initiates the activity and Lauri engages in similar activity after observing Onni. They each create specific interpretations in relation to the physical space (bench) (e.g. Soja 1996), while the other children pay more attention to the adult reading a book and remain distanced from the bench.

First, Lauri's and Onni's act of 'walking on the bench' is ignored by the educator (Kaarina, nursery nurse). However, the entry of the other educator (preschool teacher) and her comment on the situation ('Oh my, what're our little boys up to now!') triggers an account from the educator who was already present in the room. Ritva's comment makes space for climbing and walking on bench as the central feature of the setting, directing everybody's focus onto the boys. Kaarina, however, doesn't show any surprise, but offers a legitimate account of why the boys are doing what they are, and particularly, why she as a responsible educator was allowing the 'climbing space' to happen: 'We were just learning how to walk on the bench.' By saying this, she justifies her withdrawal from the situation and her acceptance of what was going on. In her account, she implies that the children had acquired the necessary skills for walking and standing on the bench; with the same account she also justifies the children's interest in walking on that particular occasion. Walking was a 'natural' continuum from the morning's previous activities, which Ritva had not witnessed. With this short 
account Kaarina implicitly refers to the unwritten rules of the day care centre, that the educator present in the situation with the children is also responsible for the wellbeing and security of the whole child group present.

Interlinked with the embodied actions of the boys, the situation unfolds and gains interpretations through the educators' comments. After the initial comments, Ritva and Kaarina both refer to the skills required for the action and evaluate the skills of the boys ('that Lauri is a bit small'... 'takes a bit of practice, 'It's a lot safer with Onni...[Lauri's] still so small'), re-establishing and defining the limits for allowed and forbidden actions as the scope of the action space. With her comments Ritva invites Kaarina to engage in the evaluation, and towards the end of the episode gives similar accounts to Ritva on the performance of the boys ('Well done! Good!). What was previously a neutral situation becomes redefined as challenging, and the act of walking on the bench becomes a challenge that the boys managed to overcome as a personal achievement. When a third child, Rasmus, attempts to join in, however, he is discouraged from doing so. In his case, the educators lack certainly regarding his ability. In contrast, in Onni's case the concern is more to do with his position on the chair ('not on the edge') rather than preventing the act of climbing, as he had been judged by the educator as having the ability to climb safely. The act of climbing and walking is allowed according to the skills previously witnessed and agreed by the educators who define the scope of the action space.

In this episode, the focus of attention is on evaluating skills; who can walk on the bench and whose walking is safe enough? Those with the required the skills, as observed by the educator, are allowed the privilege of practising further. Having the right skills creates a privileged position within the socially produced space (Soja 1996; Bourdieu 2000). The space, produced jointly by the educators and children, reflects both the educators' responsibility for ensuring safety as well as the children's individual agency. In negotiating the nature of the situation, the educators attempt to redefine the boundaries of their roles both as educators responsible for the safety of the children and as practitioners and educators whose aim is to encourage the children's active agency and experimental learning in relation to their physical environment. As a result, the children's right to participation becomes hierarchical, re-defined and characterized in relation to their skills. As demonstrated, the educators allow children's agency in diverse ways for different individuals. They define the pedagogical space that is available to the children.

Stepping back to examine the institutional structure as a whole, we can observe that the bench episode is actually situated at the borderline between 'free play' and organized activity. In general, ECE in Finland, including children's daily routines in day care centres, is characterized by alternating adult-led and free play situations. There is a structural difference between the two. In general, 'free play' is more flexible: children are either offered various activity (play) options to choose from or, as in the examined episode, the activity unfolds according to the initiatives of the children and their interests in relation to the other children, educators and the toys present. The episode occurs during the unplanned 'free play' session of the day, which differs from adult-led situations in its broader structural scope and definition of what the children can and cannot do. In other words, the 'Firstspace' (physical space) is given various interpretations according to the daily routines of the day and how each situation is defined (Soja 1996). What can be done with the bench and what actions are acceptable in that space varies throughout the day: physical training (walking) on the bench is accepted and even preferred during the 'organized learning' period, whereas the bench is for sitting during 'circle time', and so forth for each adult-planned pedagogical space. However, in the examined episode, from the children's perspective the 'walking on the bench' activity practiced previously can be continued, but for the educators the situation is now characterized as 'free play' and is subject to different rules (including no walking on the bench). 
This structural condition triggers the educators' joint interpretation of the spaces from the perspective or lenses of safety and educator responsibility. Ritva makes this clear not only verbally but also by rearranging the physical environment (moving chairs away).

The children also recognize the special value of the activity of climbing and walking on the bench. They follow each other's initiatives, join in the activity, and closely observe the educators' reactions at various points. The situation not only involves defining personal skills, but also active negotiation of the boundaries of the action space; how far and via what diverse routes, different from others, can the children take their experimentation. In their accounts and negotiations the educators participate in defining the special nature of the spaces, making it easier for the children also to identify the activity as being special and available only to them individually.

\section{EPISODE 2: High jumping}

The next episode comprises a selection of actions around a high jump stand in a preschool group of six-year-olds. The actions took place over several days during outdoor free play. On the first day the teacher set up the stand, after which the children arranged the setting each day independently. The following episode is reconstructed from three separate days.

Day 1

The teacher sets up a high jump stand in the yard of the day care centre. There is no mattress, so she spreads blankets to help cushion the ground. The teacher warns the children (six-year-olds) several times that the blankets are not very soft and advises them to land on their feet. A number of children gather around the stand; some watch while others try jumping once or twice. A long line of children forms to take part in jumping.

Matti, misses his jump.

Elli shouts: 'Matti missed!'

The teacher says that there is no reason to shout if someone misses, everyone is doing his or her best.

Elli clears the bar. Aaro is also jumping. It seems to be easy for him.

Elli fails her first attempt at the fourth level (approx. $40 \mathrm{~cm}$ high). Aaro and Matti cheer when Elli misses her jump.

Aaro cheers for Matti and shouts: 'You can do it!'

Laura and Elli come back for another jump. Nearby, some girls are baking sand cakes and setting out a pretend cake shop.

Laura: 'I'm going to the cake shop.'

Elli: 'Ok. I'll stay here. Buy something for me too.'

Irina jumps and misses her height.

In the queue, Elli says to Irina: 'I crossed my fingers that you'd miss.'

Otto also comes to jump. Aaro raises the bar.

Otto shouts from the queue: 'No-one will jump that. It's way too hard.'

The bar is at the sixth level (approx. $60 \mathrm{~cm}$ ). Matti attempts but fails.

Elli: 'The one who clears that is the best.' 
Otto passes. Elli fails. Aaro dives over and the teacher tells him to stop before he hurts himself. Several children attempt the jump. Aaro then asks for the bar to be lowered to the forth level. It is lowered to the fifth level. Aaro, Matti and Elli are the only jumpers left in the queue.

Day 2

It is Matti's turn to jump. He is clearly determined to clear the height this time, but nevertheless hits the bar. Matti starts lowering the bar.

Elli shouts from the queue: 'He's lowering it! He's embarrassed!'

'I'm not embarrassed', Matti says and, in response, raises the bar instead.

Matti: 'Now it's at the fifth level.'

The bar is hollow. Elina and Otto hold it in their hands and peer at each other through it. After a while Otto tells Elina to put the bar to her ear. Elina does so. Otto puts sand in the bar and tips it into her ear.

Day 3

Matias and Petri are playing at the high jump stand. Matias suggests doing the limbo. Petri asks what that means, so Matias demonstrates. The boys stay chatting to each other next to the stand. They pick up the bar and use it as a phone.

Petri asks: 'How are you?'.

He shouts into the bar and then raises it to his ear. They then both put the bar in their mouths and mumble. The teacher tells them to stop that because the bar is dirty. Matias heads off towards the yard shed and waves to Petri to follow.

At the beginning of the episode the teacher introduces the new high jump objects to the children while setting up the stand. For the children, this constructs a space for sport. The teacher introduces the activity to the children, but the situation is otherwise not guided by the teacher. The main focus of the teacher's input during the activity is on ensuring the children's safety, both physically and mentally. Although the teacher constructs a space for a sporting activity, during her introduction she discourages the children from commenting on each other's jumping ability. She uses pedagogical phrases to emphasize how everybody's performance is equally important and intervenes when children laugh at each other's performances. Through these comments and actions the teacher constructs space pedagogically. However, the children begin to construct a competitive sport setting: some children remain as spectators, others engage in the competition.

Within this setting the children move smoothly back and forth between different spaces, which they construct in parallel: from high jump to pretend play and back. A good example of this is how Elli places an order for a sand cake while jumping ('Ok. I'll stay here. Buy something for me too.'). The high jump stand is also used for other purposes than jumping. Elina and Otto transform the bar into a spyglass. Otto uses the bar to play a trick on Elina, tipping sand into her ear. Matias and Petri also find alternative ways to use this object: instead of jumping over the bar, they limbo under it. Moments later the bar morphs into a phone. In other words, the same object, affordance and physical 'Firstspace', gain various kinds of actualization and meanings in the children's activity (Soja 1996).

The children's actions and interactions indicate that the space involved in the examined episode is used not only for physical activity but also for outlining the children's mutual relationships and positions within their peer group (Bourdieu 2000). One indicator of this is how the children cheer or jeer at one another when clearing or missing a jump (e.g. 'Matti missed; 'You can do it!'). Ranking 
by results is an essential part of any adult high jump competition, and the same goes for this sport space ('The one who clears that is the best.').

Some of the children's attitudes, observable in both verbal and nonverbal communication, reflect the importance of success in the game. The actions of participants Matti and Elli, in particular, indicate that the space is significant to them (e.g. Elli: 'He's lowering it! He's embarrassed!' Matti: 'I'm not embarrassed'). Matti and Elli use their skill at high jump as a means of power negotiation, to define their relationship and position in the group. They define this space together, constructing it within a frame in which the sport competition serves the purposes of defining the peer group's social space. At the same time, some of the other children ignore the high jumping; they try it but otherwise pay little attention to it. This indicates that these kinds of negotiations about space are temporary and fluent, with changing participants. While being good at high jumping serves as an asset for the children in this particular situation, it is not a skill needed in day care in general. The more important asset is to have a 'feel for the game' (Bourdieu 2000), in other words, an awareness of different interpretations of the space, what kind of interactive social play occurs within it, and how this is played.

\section{Discussion}

We have argued in this paper that children and educators produce relational space jointly in their everyday, yet complex, social action and interactions. The space in a day care centre is constructed by children and adults in that particular institutional setting according to the cultural knowledge that they share. Both build their positions in relation to this construction from very different starting points. In large part, the educators structure activities, organize the daily schedule and arrange the physical environment, for example by offering certain toys at certain times, emphasizing particular rules and routines during the activities, and setting specific time constraints on activities. However, the children are active in constructing and negotiating with each other and the educators about the essence of situations and events. The construction of relational space is a process that is repeated again and again in action and that varies situationally. The educators' initiatives are often taken by the children as a starting point for action, but are also often ignored in favour of more powerful ideas for activity presented by other children.

In the interpretation of both episodes it was clear how central children and their mutually constituted peer relations (e.g. Markström and Halldén 2009; Monaco and Pontecorvo 2010; Musatti and Mayer 2011) were in constructing relational space. For example, in the high jump episode, two children jointly alternated between the playful activities of shopping and shopkeeping and the more competitive frame of high jumping. Both of the episodes show how children interpret each other's actions and events in different ways and often re-define situations in their favour. In the first episode, when climbing on the bench the boys mutually supported the activities of the other by silently observing and imitating their actions. In high jumping, the children used complex verbal language to define what is successful and what is acceptable as part of the high jump setting. Thus, they created new interpretations of the actions based on their possibilities for participating in the actions in this particular peer group. While the children are closely engaged and manipulating the objects (the physical space), their embodied interpretations are fuelled by the jointly constructed cultural context, the Thirdspace, which reformulates interpretations in different situations.

On one hand, action in the day care centre reflects the shared cultural knowledge that the children and educators have of this context. On the other hand, it also displays the various and alternative interpretations that are made as part of everyday life (see also Löfdahl and Hägglund 2007, Markström and Halldén 2009, Nordtømme 2012). In high jumping, for example, the bar initiated 
alternative interpretations of its use, leading to the establishment of meanings far removed from its original purpose. In addition, cultural assumptions about the activity of high jumping, as initiated and referred to by the educator, were challenged by the children by inventing alternative ways of controlling the height of the bar. Our analysis thus shows how physical spaces within the day care centre are interpreted in different ways through action. The same affordance can be used for various purposes. The cultural context is linked particularly to interpretations of what can be done, what is done and how. In this sense, the space produced within these actions is never neutral; it includes values, ideologies, preferences, regulations and rules constraining the possibilities for action.

Through the process of production of space, doxa (as shared, implicit, cultural assumptions, Bourdieu 2000) is also constituted and becomes visible in the analysis. The concept of doxa underlines the institutional structure that is (re)produced in action. In both episodes, implicit cultural assumptions of what can be done, what are the rules and what should be taken into consideration and discussed were present. Both episodes included concern for the children's safety. The educators attempted both verbally and nonverbally to prevent accidents by giving clear instructions or controlling the situation at risky moments, such as with the bench walking, where the children were in danger of falling. In the first episode, children walking on the bench created a need for verbal intervention and the educator's responsibility for safety was highlighted in the following dialogue. The cultural value of children's equal possibilities for participation became juxtaposed with an emphasis on certain children's already acquired skills. Those who were more skilled were in a more powerful position to negotiate their possibilities for alternative activities that differ from what the rest of the group is engaged in. Following this, these children gained a more powerful position in the construction of space, from the privileged position of being 'skilful' enough. They were able to actively re-define the situation in terms that are beneficial to them.

Learning and active participation in various activities are culturally highly valued in ECE institutions (see also Brembeck, Johansson and Kampmann 2004). A dilemma emerges, however, when there is a need to more closely define the boundaries of this learning and active participation how should active participation occur within the lived settings? Both of the examined episodes show how this interpretation is made in reference to the space constructed moment-by-moment within the setting (Soja 1996; Bourdieu 2000). The children's actions, progress and achievements during the activities are interpreted in relation to the institutional ECE setting, where learning is emphasised. The second episode also includes a parallel emphasis on competition, constructed among children; in other words, the high jump episode unfolds in relation to this goal and this structure is reflected in individual children's action and the interpretations given to their actions.

The episodes discussed here are sourced from two different age groups. While our aim has not been to compare the age-groups, it is possible to identify some commonalities and differences between these groups. With the six-year-olds there is a clear emphasis on verbal language, which is in marked contrast to the younger age group. In line with the results from a previous study with sixyear-olds, language serves as both an important resource and a structure for action. Speaking is an implicit part of participation in preschool, and therefore it is also a way to use power and create positions (Vuorisalo 2013 and 2015, forthcoming). With the younger group, the educators enter into activities by actively giving verbal accounts and interpretations of actions. However, in both episodes verbal language plays a key role in constructing the space. Many of the previously mentioned implicit cultural assumptions are applicable to both cases. Similarities are found in the emphasis on learning and skills, equal opportunities and safety.

The previously mentioned cultural assumptions (e.g. safety, learning, equality) together form the complex doxa of the day care centre. This leads us to the question of the stability and continuation 
of doxa (Bourdieu 2000; Deer 2008). In our interpretation, the shared, yet implicit cultural assumptions embedded in the 'Thirdspace' are not clear-cut or fixed, but transforming, unfolding and open to re-definition, while at the same time defying identification and substantiation. However, those assumptions define the choices and possibilities that the children and adults utilize when constructing space through their actions. In our analysis, it became clear that it is precisely this that makes doxa important. The analysis of doxa embeds current cultural practices in the day care setting within broader social struggles, and presents the interpretation of ECE in society on a wider, structural level.

\section{Conclusions}

In our paper, we have addressed some of the questions regarding the relational constitution of everyday life in a day care centre. By using actors and structure as the basis for discussion we have striven to gain further understanding and theoretical-methodological tools for addressing the interrelations between micro-level interactions and day care as an institution. We have analysed individual action at the micro-level, and used two examples representing everyday life in a day care centre. This is a first step in developing theoretically relational-spatial perspectives of ECE spaces. However, there is a need for wider micro-level analyses to reveal the common ideas and understandings at play in ECE settings. The relational approach used revealed how structural terms are present in each interaction situation. Although the starting point for the analysis is individual action, the focus is on the relations between individuals and between individuals and structures. By applying relational tools theoretically and methodologically in ECE research we are also able to achieve more ongoing and relationally determined, rather than merely situationally negotiated, conditions in interaction situations. Everyday life in a day care centre is deeply embedded in the wider institutional, cultural and historical context of ECE.

\section{References}

Alderson, J., and K. Jones. 2009. The difference that place makes to methodology: Uncovering the ‘lived space’ of young people’s spatial practices. Children’s Geographies 7 (3): 291-303.

Altman, I. and B. Rogoff. 1987. World view in psychology: trait, interactional, organismic, and transactional perspectives. In Handbook of environmental psychology 1, edited by D. Stockols and I. ltman. New Yok: John Wileys, 7-40.

Bourdieu, P. 2000. Pascalian meditations. Stanford, CA: Standford University Press.

Brembeck, H., B. Johansson and J. Kampmann, eds. 2004. Beyond the Competent Child. Exploring Contemporary Childhoods in the Nordic Welfare Societies. Roskilde: Roskilde University Press.

Deer, C. 2008. Doxa. In Pierre Bourdieu. Key concepts, edited by M. Grenfell, 119-130. Stocksfield: Acumen.

Einarsdottir, J. 2005. Playschool in pictures: children's photographs as a research method. Early Child Development and Care 175, (6): 523-541.

Emilson, A. and A-M. Folkesson. 2004. Children's participation and teacher control. Early Child Development and Care 176 (3-4): 219-238. 
Gallacher, L. 2005. “The terrible twos”: Gaining Control in the Nursery? Children's Geographies 3 (2): 243-264.

Gibson, J. J. 1977. The theory of affordance. In Perceiving, acting and knowing. Towards an ecological psychology, edited by R. Shaw and J. Bransford. Hillsdale: Lawrence Erlbaum, 67-82.

Harker, C. 2005. Playing and affective time-space. Children's geographies 3 (3): 47-62.

Harrison, L., and J. Sumsion, eds. 2014. Lived Spaces of Infant-Toddler Education and Care. Exploring Diverse Perspectives on Theory, Research and Practice. New York: Springer.

Heft, H. 2003. Affordance, dynamic experience, and the challenge of reification. Ecological Psychology 15, (2): 149-180.

Kallio, K.P., and J. Häkli. 2013. Children and Young People’s Politics in Everyday life. Space and Polity 17 (1): 1-16.

Kjørholt , A.T. and M. Seland. 2012. Kindergarten as a bazaar: Freedom of choice and new forms of regulation. In Modern child and the flexible labour market: Early childhood education and care, edited by A.T. Kjørholt and J. Qvortrup. Basingstoke: PalgarveMacmillan, 168-185.

Lefebvre, H. 1991. The Production of Space. Malden, MA: Blackwell publishing.

Löfdahl, A., and S. Hägglund. 2007. Spaces of participation in pre-school: arenas for establishing power orders? Children and Society 21: 328-338.

Mannion, G. 2007. Going spatial, going relational: Why “listening to children” and children's participation needs new reframing. Discourse: Studies in the Cultural Politics of Education 28 (3): 405-420.

Markström, A-M. 2010. Talking about children's resistance to the institutional order and teachers is preschool. Journal of Early Childhood Research 8 (3): 303-314.

Markström, A-M., and G. Halldén. 2009. Children’s Strategies for Agency in Preschool. Children \& Society 23: 112-122.

Monaco, C., and C. Pontecorvo. 2010. The interaction between young toddlers: constructing and organizing participation frameworks. European Early Childhood Education Research Journal 18 (3): 341-371.

Musatti, T., and S. Mayer. 2011. Sharing attention and activities among toddlers: the spatial dimension of the setting and the educator's role. European Early Childhood Education Research Journal 19 (2): 207-221.

Nordtømme, S. 2012. Place, space and materiality for pedagogy in a kindergarten. Education Inquiry 3 (3): 317-333.

Olwig, K., and E. Gulløv, eds. 2003. Children’s Places: Cross-Cultural Perspectives. London: Routledge. 
Pessanha, M., Aguiar, C. and Bairrão, J. 2007. Influence of structural features on Portuguese toddler child care quality. Early Childhood Research Quarterly (22): 204-214.

Raittila, R. 2008. Retkellä. Lasten ja kaupunkiympäristön kohtaaminen. [Making a visit. Encounters between children and an urban environment.] Jyväskylä Studies in Education, Psychology and Social Reseach 333. Jyväskylä: University of Jyväskylä.

Raittila, R. 2012. With children in their lived place: children's action as research data. International Journal of Early Years Education 30 (3): 270-279.

Rutanen, N. 2012. Socio-spatial practices in a Finnish daycare group for 1 to 3-year-olds. Early Years: An International Journal of Research and Development. Special issue on working with under-threes 32 (2): 201-214.

Rutanen, N. 2014. Lived spaces in a toddler group - application of Lefebvre's spatial triad. In Lived Spaces of Infant-Toddler Education and Care, edited by L. Harrison and J. Sumsion. New York: Springer, 17-28.

Ryan, K. W. 2012. The new wave of childhood studies: Breaking the grip of bio-social dualism? Childhood 19 (4): 439-452.

Skelton, T. 2013. Young People, Children, Politics and Space: a Decade of Youthful Political Geography Scholarship 2003-13. Space and Polity 17 (1): 123-136.

Soja, E. 1996. Thirdspace. Journey to Los Angeles and other real-and-imagined places. Cambridge MA: Blackwell.

Sylva, K. 2010. Quality in early childhood settings. In Early Childhood Matters. Evidence from the Effective Pre-school and Primary Education project, edited by K. Sylva, E. Melhuish, P. Sammons, I. Siraj-Blatchford and B. Taggart. London: Routledge, 70-91.

Vuorisalo, M. 2011. Children's resources in action - The conversion of capital in the field of daycare. In Fields and Capitals: Constructing Local Life, edited by L. Alanen and M. Siisiäinen. University of Jyväskylä: Institute for Educational Research, 29-60.

Vuorisalo, M. 2013. Lasten kentät ja pääomat. Osallistuminen ja eriarvoisuuksien rakentuminen. . [Children's Fields and Capital. Participation and the Construction of Inequality in Preschool.] Jyväskylä Studies in Education, Psychology and Social Research 467. Jyväskylä: University of Jyväskylä.

Vuorisalo, M. and Alanen, L. 2015, forthcoming. Early Childhood Education as a Social Field: Everyday Struggles and Practices of Dominance. In Childhood with Bourdieu, edited by L. Alanen, L. Brooker and B. Mayall. Basingstoke: Palgrave Macmillan. 